\title{
O debate contemporâneo sobre a gestão social`
}

\author{
The contemporary debate on social management
}

\author{
Ademir Alves da Silva*
}

\begin{abstract}
Resumo:
O presente texto consiste em reflexão crítica sobre as tendências da gestão social, entendendo que a despeito da disseminação e da generalização, na década de 1990, do uso da expressão gestão social, sob perspectiva multidisciplinar, a mesma constitui objeto da intervenção profissional do Serviço Social brasileiro desde a gênese da profissão, no Brasil, na década de 1930, ainda que sob diferentes abordagens, tributárias de projetos societários oponentes. A gestão social ocupa-se da reprodução da vida social respondendo, direta ou indiretamente, às exigências da esfera da produção. Tendo como objeto a provisão de bens e serviços, privilegia o equacionamento de demandas sociais, opondo-se à lógica mercantil. Arena de lutas por acesso à riqueza social e à participação social e política, a gestão social é abordada sob a perspectiva de busca de alternativas em direção a uma sociedade igualitária e justa.
\end{abstract}

Palavras-chave: Serviço social. Gestão social. Política social. Seguridade social.

\begin{abstract}
:
This text presents a critical reflection about social management trends. In spite of the widespread and generalized use of the expression social management in the 1990's, it constitutes, under multidisciplinary perspective, the object of professional intervention of the Brazilian Social Work, since the genesis of the profession in Brazil, in the 1930's, even under different approaches, that have promoted opposite society projects. The social management involves the reproduction of the social life, responding, either direct or indirectly, to demands of the production sphere. Its object is the goods and social services provision, emphasizing the solution of the social demands, in opposition to the mercantile logic. Social management has been the arena of struggles for access to social wealth and social and political participation; it is studied under the perspective of searching alternatives toward an egalitarian and just society.
\end{abstract}

Key words: Social work. Social management. Social policy. Social security.

\footnotetext{
- Exposição em mesa redonda compartilhada com a Profa. Dra. Mariângela Belfiore Wanderley no Seminário Nacional: Gestão de Políticas Sociais e Território, realizado nos dias 2 e 3 de abril de 2013, por iniciativa do Núcleo de Estudos e Pesquisas em Gestão de Políticas Sociais do Programa de Pós-Graduação em Serviço Social e Política Social da UEL - Universidade Estadual de Londrina, no âmbito do PROCAD, em parceria com o Programa de Estudos Pós-Graduados em Serviço Social da PUC-SP.

* Assistente Social, Doutor em Serviço Social e Políticas Sociais pela PUC-SP, Professor do Programa de Estudos PósGraduados em Serviço Social da PUC-SP, onde coordena o Núcleo de Estudos e Pesquisas sobre Políticas Sociais. Membro da equipe do PROCAD no âmbito da parceria entre a UEL e a PUC-SP. adecris@uol.com.br
} 
A intenção, com o presente texto, é identificar traços constitutivos e tendências da gestão social contemporânea, de modo a subsidiar o debate e as decisões sobre as políticas sociais brasileiras. Com esta segunda parte da exposição pretendo compor com a professora Mariângela, que me precedeu, alguns argumentos quanto à gestão social em sua relação com o Serviço Social.

Citando trecho de minha tese de doutorado, desejo ressaltar, em primeiro lugar, o entendimento de que

A despeito da disseminação e da generalização, na década de 1990, do uso da expressão gestão social, sob perspectiva multidisciplinar, a mesma constitui objeto da intervenção profissional do Serviço Social brasileiro desde a sua gênese na década de 1930, ainda que sob diferentes abordagens, tributárias de projetos societários oponentes:

a) o conservadorismo católico sob a pretensa equidistância entre o liberalismo e o socialismo;

b) a consolidação da socialidade burguesa em diferentes estágios (o "espírito social" do empresariado das primeiras décadas do século $\mathrm{XX}$, o controle social estadonovista, o desenvolvimentismo, a modernização conservadora da ditadura militar, a reforma e a contra-reforma da década de 1980, o projeto neoliberal);

c) e a perspectiva de questionamento e ruptura com os modos dominantes de pensar a sociedade e suas influências na área profissional, buscando alternativas no âmbito de um projeto societário escorado em valores democráticos de horizonte socialista (Silva, 2013, pp. 33-34)

Lá estavam os assistentes sociais, de alguma maneira, aderindo àqueles projetos ou contrapondo-se a eles, insurgindo-se eventualmente, servindo, consciente ou ingenuamente a projetos de Brasil, a projetos de sociedade, na condição de gestores sociais.

A Professora Mariângela discorreu sobre os traços constitutivos da gestão social e os elementos conceituais básicos. E o que vemos? Para nós, assistentes sociais, o social, de adjetivo se converte em substantivo pela relevância profissional e acadêmica do serviço social, da seguridade social, da proteção social, da gestão social, do bem estar social.

Trabalhadores intelectuais que somos, intelectuais da área de humanidades, intelectuais dirigentes da vida social, o social é para nós o substantivo, no sentido de que ocupa nossas agendas, o nosso tempo e consome nossas energias.

O Serviço Social comparece a todos aqueles momentos históricos. A professora Mariângela mencionou Teresópolis. Eu quero recuar um pouco mais no tempo e mencionar, pelo menos, Araxá em 1967, ocasião em que se acentuava o papel do Serviço 
Social e as funções das/os assistentes sociais no planejamento, na administração e na implantação de "recursos sociais". É arbitrária essa minha escolha do marco de 1967, poderia ser outra referência. Teresópolis, em 1970, enseja uma discussão sobre os "níveis de atuação" do Serviço Social, dentre os quais a política social, o planejamento e a "administração de Bem-Estar Social", a par da prestação direta de serviços. Balbina Ottoni Vieira, em 1979, publica uma obra sob o título, Serviço Social - Política e Administração, com dois capítulos dedicados ao "planejamento, organização e administração do Serviço Social".

A lei n. 8.662/93, que regulamenta a profissão de assistente social, estabelece em seu artigo $4^{\circ}$ as competências do assistente social. Tais competências desenham a figura do gestor de políticas sociais.

Em 1999, o então IEE - Instituto de Estudos Especiais e que agora é a CEDEPE Coordenadoria de Estudos e Desenvolvimento de Projetos Especiais, que a professora Mariângela dirige, publicou uma coletânea de textos a partir da realização de um evento. A coletânea foi organizada pelas professoras Raquel Raichelis e Elizabeth de Melo Rico, sob o título Gestão Social, uma questão em debate. Agora em 2013, está prevista a publicação de uma revista, Gestão Social, do FONSEAS, que é o Fórum Nacional dos Secretários de Assistência Social. Estão lá os intelectuais, os gestores sociais, a lista dos colaboradores assistentes sociais em maioria - mencionados na contracapa.

Estou fazendo essas rápidas referências, apenas para marcar nossa vinculação com a Gestão Social nos vários momentos históricos e nos vários projetos societários em confronto, conforme as posições teóricas e ético-políticas assumidas. Em uma vertente ou noutra, nesse gradiente de posições que marcam a luta social e a disputa pelo acesso à riqueza social no âmbito do Estado e da sociedade civil, estamos nós os assistentes sociais, na condição de gestores sociais.

A presente reflexão sobre a gestão social define-se por uma perspectiva de crítica e de ruptura com os modos dominantes de pensar a sociedade, tecendo caminhos de uma razão insurgente em face da ordem social burguesa. Trata-se de buscar alternativas humanizantes e justas na gestão da vida social, em um campo que se afasta e que se opõe aos projetos moderno-conservadores, em favor de um projeto societário apoiado em valores democráticos. 
O que é gestão social? Com base em um balanço da literatura acerca da temática da gestão social, a Assistente Social Marilene Maia (2005) afirma que:

... compreendemos a gestão social como um conjunto de processos sociais com potencial viabilizador do desenvolvimento societário emancipatório $e$ transformador. É fundada nos valores, práticas e formação da democracia e da cidadania, em vista do enfrentamento às expressões da questão social, da garantia dos direitos humanos universais e da afirmação dos interesses e espaços públicos como padrões de uma nova civilidade. Construção realizada em pactuação democrática, nos âmbitos local, nacional e mundial; entre os agentes das esferas da sociedade civil, sociedade política e da economia, com efetiva participação dos cidadãos historicamente excluídos dos processos de distribuição das riquezas e do poder. Estes referenciais apontam a práxis da gestão social, enquanto mediação para a cidadania, que se contrapõe à perspectiva instrumental e mercantil que vem sendo dada a este tema (...) o Serviço Social constitui-se em mediação importante para a afirmação da práxis da gestão social, especialmente pelo conjunto de compromissos e referenciais éticopolíticos, teórico-metodológicos e técnico-operativos, que objetivam a afirmação dos valores da cidadania, democracia e justiça social, tanto quanto a gestão social. Além disso, os profissionais dessa área acumulam competências $e$ habilidades importantes no sentido de desvelar e atuar junto à realidade social e à população, que se constitui na centralidade do processo da gestão socia" (grifos meus)

Mas, vale ressaltar que, a partir da década de 1990, a expressão gestão social ganha relevo e força semântica e simbólica, sob outra perspectiva. A gestão social mostra-se in fashion e up-to-date.

Nós já fazíamos - sempre fizemos - gestão social, que passou à agenda dos governantes, dos intelectuais, dos partidos políticos, das universidades, das diversas instituições. Não por acaso. A gestão social passa a ser enfatizada em um particular contexto histórico de implantação da estratégia neoliberal no mundo todo, a partir das diretrizes do Fundo Monetário Internacional e do Banco Mundial.

No Brasil, a gestão social, envolta em semântica de apelo ao chamado terceiro setor, ao voluntariado, às organizações da sociedade civil e ao próprio mercado, ganha força no contexto da reforma neoliberal, em que se preconizava a redução do papel social do Estado e o fomento ao mercado.

Sob essa perspectiva, foram adotadas algumas medidas abrangendo parcerias com a sociedade civil, transferências de responsabilidades do Estado para agentes do mercado ou da sociedade civil e privatizações, como aconteceu com várias empresas públicas estatais.

E foi se impondo o conceito de público, não necessariamente estatal. Compartilhamos dessa concepção de uma esfera pública mais abrangente, esfera pública 
que não é sinônimo de estatal, mas nós queremos mais. Trata-se, como disse a Professora Mariângela, de ampliar a esfera pública. Trata-se de dar sentido público às nossas causas e às nossas lutas, pensar a sociedade com esse senso de coletivo, com esse senso de espécie humana, de humanidade.

Trata-se de pensar a riqueza como algo que é de todos, exercício do poder como algo que é de todos. Então, interessa-nos essa concepção mais abrangente do público, para além da esfera estatal stricto sensu. Mas essa abordagem também traz armadilhas. Que tipo de armadilha? O de utilizar o pretexto do público não estatal para a desobrigação do Estado quanto às políticas sociais ou para a redução do papel social do Estado.

As duas últimas reformas da previdência social - a de 1998, sob a gestão de Fernando Henrique Cardoso e a de 2003, sob a gestão de Luiz Inácio Lula da Silva - ocorreram em contexto de hegemonia do pensamento neoliberal, do Estado mínimo, das privatizações, dos estímulos ao mercado.

Naquele contexto prevalece a concepção de Estado fomentador do mercado tendo na agenda modelos híbridos de gestão social pela articulação estatal-privado e estratégias semi-privatizantes ou privatizantes de serviços de interesse público.

Na esfera da chamada responsabilidade social corporativa, do mundo das empresas, observou-se uma profusão de estratégias de marketing social, sob a intenção de agregar valor ao negócio e de ampliar as taxas de lucro. Nesse caso, os declarados fins sociais correspondem, em última análise, a fins econômicos, à busca de maior rentabilidade, aos propósitos de ampliação dos negócios e de veiculação de imagem positiva do negócio, associando um "bom sentimento", uma "boa ideia" a um logotipo, logomarca de uma empresa.

Portanto, a gestão social ganha força sob um clima retórico e fático de desobrigação do Estado. Desobrigação que acontece aqui e ali na forma de terceirizações, parcerias, modelos híbridos ou mistos de gestão social, mediante um processo incrementalista de privatização.

Na área da educação, por exemplo, o processo de mercantilização e de privatização, já vem de muitas décadas. Na área da saúde não tem sido diferente, mas as medidas privatizantes intensificam-se em período recente. $\mathrm{Na}$ área da assistência social desenvolveu-se um percurso inverso, para dentro do Estado, ao se levantar a bandeira da 
assistência social como política pública, dever do Estado, direito do cidadão. Ao ter que se afirmar na esfera pública, a política de assistência social avançou, de certo modo, na contramão das estratégias por menos Estado e mais mercado. A execução dos serviços sócio assistenciais segue a cargo das organizações sociais filantrópicas, no âmbito privado, mas é notória a ampliação da intervenção estatal no planejamento, monitoramento, avaliação, regulação e financiamento da Política de Assistência Social.

A assistência social teve que se afirmar como política pública e o Estado é o lugar, não é o único, nem exclusivo, mas é o lócus por excelência da gestão social e das políticas sociais.

Destarte, julgo importante retomar esse contexto da década de 1990 com suas reverberações em nossa agenda mais recente, no âmbito da gestão social, para que estejamos atentos às armadilhas teóricas, ideológicas, de uma retórica que se vale de um arranjo semântico de apelo à solidariedade, prestando-se a servir à revitalização da economia capitalista em crise. E nós nos associamos aos movimentos de resistência em favor das lutas das camadas sociais subalternizadas por acesso à riqueza.

Permitam-me citar um exemplo extraído de minha experiência como conselheiro do COMAS, que é o Conselho Municipal de Assistência Social da cidade de São Paulo. Em um dos eventos eu perguntei: - Pessoal, o que estamos fazendo aqui no Conselho?

A começar pela sigla COMAS, era aquela coisa chata, burocrática, cartorial, aquelas reuniões intermináveis, administrativistas, burocratizadas, insuportáveis. E eu erguia o dedo para dizer: o COMAS é um lugar de luta por poder e riqueza!

Causava estranhamento, destoava da agenda qualquer questionamento que eu apresentasse naquele contexto de muitos processos, atas e pareceres.

Ora, eu dizia, o Conselho de Assistência Social é lugar de luta por acesso a duas coisas, poder e riqueza. Vamos fazer com que os nossos lugares na gestão social, sejam lugares de ampliação da luta pela conquista de duas coisas que são poder e riqueza.

Não se trata do poder na restrita acepção palaciana, mas é poder de falar, é o poder de expressão, é o poder de lutar, é o poder do sindicato, do partido, dos estudantes, das mulheres, dos negros, dos quilombolas, um poder que se exerce na vida social, nas várias esferas da vida social, sob uma concepção ampliada de exercício do poder, que não se restringe ao poder instituído, ao espaço palaciano dos poderes públicos. 
Não se trata da riqueza, essa que nós criticamos, perdulária, parasitária, do capitalismo financeirizado, do capitalismo desregulamentado, ganancioso, que leva o mundo inteiro a uma crise sem precedentes. Refiro-me à riqueza socialmente produzida, patrimônio coletivo.

Como na música dos Titãs, "a gente não quer só comida, a gente quer comida, diversão e arte." É a acepção mais ampla de riqueza: eu quero pertencer, quero participar, quero ter acesso à riqueza material, mas quero ter acesso à cultura, ao lazer, às crenças, aos valores.

A gestão social ocupa-se da reprodução da vida social respondendo, direta ou indiretamente, às exigências da esfera da produção. Tendo como objeto a provisão de bens e serviços, privilegia o equacionamento de demandas sociais, opondo-se à lógica mercantil.

Não se trata de reprodução social em si mesma, dissociada da produção. A reprodução social responde de um jeito ou de outro, direta ou indiretamente, à esfera econômica. Não estamos isolados na esfera da reprodução social. Estamos vinculados, queiramos ou não, ao mundo da produção, ao mundo do trabalho. A política não se separa da economia. Nós, assistentes sociais, não lidamos com coisas, mercadorias, lidamos com pessoas que são trabalhadores e que produzem meios e bens para a satisfação de necessidades humanas.

Sob a primazia da responsabilidade do Estado, a gestão social constitui um gradiente de iniciativas dos poderes públicos e da sociedade civil, tendo como foco as demandas coletivas e o interesse público. Seus fins são o acesso a direitos sociais e a conquista da cidadania. Seus meios articulam-se em um desenho estratégico-operativo multidisciplinar, intersetorial, e territorializado. As estratégias econômicas constituem meios em favor de fins sociais: qualidade de vida e bem estar social.

Então, a gestão social põe em questão a lógica mercantil, pois se desenvolve na esfera de um consumo social. No caso da Assistência Social, independentemente de contribuição prévia, até porque os usuários dos serviços podem estar fora do mercado de trabalho, não do mercado de consumo, mas do mercado de trabalho. Ou podem estar precariamente inseridos no mercado de trabalho.

A Professora Mariângela enfatizou a esfera do público. Ora, a gestão social se ocupa dos negócios de interesse público, da coisa pública, da res pública, sob a primazia da 
responsabilidade do Estado. Seus fins são o acesso a direitos sociais e a conquista da cidadania. Isso não é pouca coisa. Lutar por direitos sociais na América Latina, no Brasil, é lutar contra a pobreza e a desigualdade social buscando acesso ao poder e à riqueza. É mudar a qualidade de vida, é buscar conforto e bem estar social.

Em suma, ao operar no âmbito do acesso a bens e serviços, sob perspectiva não mercantil, buscando alternativas de respostas às demandas sociais, a gestão social responde pela unidade contraditória entre Estado, mercado e sociedade civil, promovendo a coesão e alimentando o consenso em torno do projeto societário dominante. Mas, pode igualmente contribuir para desfazer consensos, pondo em questão as formas de produção e de fruição da riqueza social, sob critérios universalistas de justiça social.

Ora, quem promove consenso, pode promover o dissenso. O assistente social é um trabalhador intelectual, gestor de políticas sociais, que supervisiona, coordena, organiza, forma opinião, informa, estabelece protocolos, articula parcerias e redes, gerencia e monitora recursos, presta serviços. O Assistente Social é um trabalhador intelectual que promove consensos em favor de determinada coesão social e que, por outro lado, também pode colocar em questão o consenso, exercendo a crítica social no âmbito da gestão social, desfazendo o consenso.

A Professora Mariângela fez isso em vários momentos de sua exposição, quando afirmava: não é reparador, não é assistencialista, não tem que ser compensatório. Há consensos em torno dessas concepções. Então, ela está dizendo: Vamos desfazer esses consensos e promover novos consensos em torno da política social, da cidadania, da resistência e da luta, como eu dizia, por acesso a duas coisas, riqueza e poder.

Assumir tal posição, não sejamos ingênuos, vai colocar-nos em uma situação de questionar as formas de produção e de fruição da riqueza social. Quais são os critérios que nos informam em nossas aulas, em nossas teses, em nossas dissertações, em nossos eventos? Os nossos critérios são critérios universalistas de justiça social. Não estamos aqui, em um evento como esse, para promover a competição, o individualismo, o capitalismo financeiro, a ganância, o levar vantagem em tudo.

Estamos aqui movidos, animados, por uma utopia universalista de justiça social, de equidade, contra todas as formas de desigualdade social, a desigualdade de renda, a desigualdade de gênero, a desigualdade étnico-racial, a desigualdade sócio-territorial. 
O lugar em que você mora, o lugar onde você vive, onde você trabalha, o lugar faz a diferença, o lugar, o topos. Por isso a utopia, ou topos, o não lugar, eu quero chegar lá, eu quero chegar para construir lugares ou espaços em que se possa viver com dignidade, que sejam habitáveis, que não sejam hostis e inóspitos, que não sejam desconfortáveis, que não sejam desumanos e injustos.

O topos, nos remete a lugar, à questão do lugar, que é objeto desse seminário, o território. Estou certo de que a Profa. Dirce Koga, no período da manhã, já elucidou amplamente essa questão do território.

A crise contemporânea, intensificada a partir do crash de 2008, repõe na agenda de governantes, social policy makers, intelectuais e gestores sociais, o recorrente trade off das escolhas e decisões, ao opor políticas econômicas e fiscais a políticas sociais, invariavelmente em prejuízo destas últimas.

Ganha visibilidade a intensa disputa pela riqueza social, especialmente por meio do acesso a parcelas do excedente econômico apropriado pelo Estado, mas também pelos mecanismos do mercado e das alternativas SFL (sem fins lucrativos). Ora, a gestão social constitui arena de disputa pelos recursos do fundo público.

No contexto da crise, impõe-se o paradoxo: ampliam-se as demandas sociais, mas esvanece a vontade política de equacioná-las e reduz-se a disponibilidade de recursos para as políticas sociais.

Não obstante, o objeto da gestão social não se alterou. Esse objeto, como dizia a Mariângela, relativo às demandas sociais, à participação social, ao controle social, tudo isso que ela apontou com clareza didática e com a ajuda do power point, esse objeto não se alterou. Na segunda década do terceiro milênio o desafio segue sendo o combate às diversas manifestações da desigualdade social: de renda, de gênero, étnico-raciais e sócioterritoriais. Gerir o social, hoje, equivale a ocupar-se das estratégias para combater o desemprego e das questões relacionadas à imigração e à proteção social.

Os principais problemas da gestão social remetem às relações entre política e economia em contexto de constante sujeição daquela por esta última. Não é por acaso que no filme, Inside Job - Trabalho Interno -, de 2010, de Charles Ferguson, um dos entrevistados afirma: - O governo é de Wall Street - para dizer da sujeição, da subordinação da política e dos próprios governos ao mundo das finanças, das grandes 
corporações. Vivemos sob a ditadura do mercado financeiro, do capital financeiro e da privatização do público.

Vejamos o que se passa na Europa hoje, particularmente na Europa do Sul, com os cortes no orçamento público, os constrangimentos ao sistema de proteção social, as reduções de benefícios sociais, as hostilidades, a xenofobia e a intolerância aos imigrantes. No momento da crise, o que já era desigual, fica um pouco mais perverso, com a austeridade fiscal, a redução dos recursos do orçamento e o ataque às políticas sociais.

E nós, gestores sociais, nos colocamos diante desse contexto perverso, em que se garante a apropriação de ganhos pelos banqueiros e pelos executivos das grandes instituições financeiras, quando o sistema financeiro quebra, aqui e ali, mas recebe a chamada injeção de liquidez com recursos públicos. Quem paga a conta é o contribuinte, é o trabalhador, é o consumidor, é a população em geral. É um contexto perverso, em que se apropriam ganhos e riqueza e, por outro lado, se socializam as perdas.

No Brasil estamos convivendo com o pibinho - diminutivo de PIB - Produto Interno Bruto -, pois há uma redução do crescimento, mas não se confirmou, pelo menos por hora, a expectativa de uma avalanche, um tsunami na economia brasileira. Não obstante, ocupamo-nos de avaliar o efetivo alcance do chamado "desenvolvimento com inclusão social" que mantém intocados os pilares da desigualdade social.

Se a crise, por um lado, nos permite cogitar acerca do esgotamento de um modelo de crescimento e desenvolvimento capitalista, do esgotamento do próprio modo de organizar a sociedade, não podemos afirmar, seria ingênuo, que o neoliberalismo tenha sido vencido, pois continua firme, vigoroso e atuante. Não é verdade que esteja esgotado e superado. Os apologistas do mercado insistem em que a economia capitalista é dinâmica e vai superar a crise e que o capitalismo não vai acabar. De fato, o capitalismo já mostrou historicamente a sua capacidade de se revitalizar e de se reformar.

Não obstante, temos um compromisso ético e político que nos move e que não nos permite uma posição de indiferença perante esse quadro, a não ser que sejamos completamente cínicos, o que não somos. Temos um projeto ético-político, que nos interpela e nos empurra para uma arena de combate pela crítica social, uma arena que requer de nós lucidez e consistência nas análises, refinamento nas pesquisas, consistência 
de propostas para exercer a gestão social coerentemente com esses valores que Mariângela e eu aqui destacamos.

No contexto da crise - a crise é fecunda nesse sentido -, ganham maior visibilidade o papel do Estado em favor do capital, o esgotamento de alternativas, o caráter perverso do neoliberalismo, os deletérios impactos sociais da desregulamentação do mercado financeiro, abrindo-se flancos dos modelos de desenvolvimento e do próprio sistema econômico para pensar e buscar alternativas.

A desqualificação da política ou a desafeição pela política, é própria de certo pensamento pós-moderno. Nós, gestores sociais vamos requalificar a esfera da política. A humanidade ainda não inventou, que eu tenha conhecimento - e eu tenho sido professor de política social por muitos anos -, parece que não inventamos ainda uma esfera mais ampla e universalista do que a esfera da política para equacionar o interesse público.

Mas, nós temos que qualificá-la, não podemos abdicar da política, como trincheira no âmbito da luta por acesso à riqueza e ao poder, segundo as concepções que aqui mencionei. Trata-se de preconizar mais Estado, justa divisão da riqueza, justa política tributária, outro modo de pensar a cidade e a propriedade imobiliária, outro modelo de gestão e ocupação da terra.

No caso da Assistência Social, temos aí a recente Norma Operacional Básica, de dezembro de 2012, a NOB - SUAS mais ousada e mais abrangente no desenho ainda mais consistente do Sistema Único de Assistência Social. Trata-se da assistência social qualificada, resolutiva, com prontidão para atender o cidadão, reconhecendo as demandas do cidadão, pois há certa assistência social que desqualifica o cidadão, que não reconhece a demanda, que exclui sob o pretexto de atender os critérios de elegibilidade.

EM SUMA, É POSSÍVEL CONCLUIR QUE a pauta do gestor social organiza-se em face de demandas que, na esfera da política, remetem ao papel social do Estado: educação como bem coletivo, saúde integral, cobertura previdenciária ampliada, garantia de renda, assistência social qualificada e resolutiva, habitação como direito social básico, cidadania da mulher não reduzida à maternidade, crianças e adolescentes como titulares de direitos, idosos respeitados e valorizados em sua seniority, acesso e apropriação da cidade como direito de todos, terra para quem nela trabalha, meio ambiente como bem coletivo e sustentável e que pertence também às próximas gerações.. 


\section{Referências}

BRASIL. Lei n. 8662, de 7 de junho de 1993. Dispões sobre a profissão de Assistente Social e dá outras providências. Disponível em:

<http://www.planalto.gov.br/ccivil_03/leis/L8662.htm>. Acesso em: 15 maio 2013.

Resolução n. 33 de 12 de dezembro de 2012. Aprova a Norma Operacional Básica do Sistema Único de Assistência Social -NOB/SUAS. Diário Oficial da União, Brasília, ano 1, n. 2, 3 jan. 2013.

MAIA, M. Gestão social:- reconhecendo e construindo referenciais. Revista Virtual Textos \& Contextos, Porto Alegre, n. 4, dez. 2005.

RICO, E. M.; RAICHELIS, R. (Org.). Gestão social: uma questão em debate. São Paulo: EDUC, 1999.

SILVA, A. A. A gestão da seguridade social brasileira: entre a política pública e o mercado. 3. ed. São Paulo: Cortez, 2012.

VIEIRA, B. O. Serviço social política e administração. Rio de Janeiro: Agir, 1979. 